\title{
Bivalirudin in percutaneous coronary intervention
}

\section{Sam J Lehman \\ Derek P Chew}

Department of Medicine, Flinders University, South Australia, Australia

\begin{abstract}
Bivalirudin is a member of the direct thrombin inhibitor group of anticoagulants. It has been evaluated as an alternative to unfractionated and low-molecular-weight heparins in the settings of percutaneous coronary intervention (PCI) and acute coronary syndrome (ACS). Results of clinical trials to date suggest bivalirudin is a viable alternative to the use of a heparin combined with a glycoprotein (GP) IIb/IIIa inhibitor in these settings. Thrombin has a central role in coagulation and platelet activation in ACS and during PCI. Its direct inhibition is an attractive target for therapy in these settings. Bivalirudin is a 20 amino acid polypeptide hirudin analog. It displays bivalent and reversible binding to the thrombin molecule, inhibiting its action. Direct inhibition of thrombin with bivalirudin has theoretical pharmacokinetic and pharmacodynamic advantages over the indirect anticoagulants. A reduction in rates of bleeding without loss of anti-thrombotic efficacy has been a consistent finding across multiple clinical trials. There may be economic benefits to the use of bivalirudin if it permits a lower rate of use of the GP IIb/IIIa inhibitors. This article reviews the pharmacology of bivalirudin and clinical trial evidence to date. There are now data from multiple clinical trials and meta-analyses in the setting of ACS and PCI. Early results from the acute catheterization and urgent intervention strategy (ACUITY) trial are discussed.
\end{abstract}

Keywords: bivalirudin, direct thrombin inhibitor, acute coronary syndrome, percutaneous coronary intervention

\section{Introduction}

Anticoagulation is required during percutaneous coronary intervention (PCI) to prevent peri-procedural thrombotic complications. Unfractionated heparin (UFH) and more recently the low molecular weight heparins (LMWHs) are the most common form of anticoagulation used during PCI (Smith et al 2005). Recently, the direct thrombin inhibitor (DTI) class of compounds has been evaluated as an alternative form of anticoagulation during PCI (Bittl et al 1995; Lincoff et al 2002, 2004a).

Bivalirudin is a member of the direct thrombin inhibitor class of compounds. The pharmacology and early trial evidence have pointed to unique benefits of this molecule. These are predictable pharmacokinetics, a reduction in bleeding complications and avoidance of heparin induced thrombocytopenia (HIT). In the clinical trials reported to date, these advantages have occurred without a loss of efficacy in thrombotic end-points.

\section{Thrombin in cardiovascular disease}

Coagulation has previously been considered as a cascade model with an intrinsic and extrinsic component meeting in a final common pathway (MacFarlane et al 1964). The last decade has provided evidence of a more complex system than the linear model first proposed. Following vessel injury, there are multiple interactions between coagulation proteins, cellular components, and the vessel wall (Becker et al 2005). The interaction between tissue factor and factor VII is an initiating event in the coagulation cascade, promoting the generation of thrombin from prothrombin. 
Thrombin is responsible for fibrin deposition, and the further activation of platelets, endothelial cells, and leukocytes. Thrombin activates platelets by binding directly to cell surface receptors. Protease activated receptor (PAR)-1 and to a lesser extent PAR-4 is particularly important for platelet activation (Andersen et al 1999; De Candia et al 2001; Soslau et al 2001). This mechanism of platelet activation is independent of prostaglandin and adenosine diphosphate. It is therefore not inhibited by aspirin or the thiopyridines such as clopidogrel. Activation of the coagulation pathway is regulated by natural anticoagulants. These are tissue factor pathway inhibitor, protein $\mathrm{C}$ and $\mathrm{S}$, and antithrombin.

The critical role of thrombin in response to local tissue injury makes its inhibition an attractive target to prevent thrombotic complications during PCI. The action of thrombin can be inhibited by binding to three domains, the active (or catalytic) site, and two exosites (Tulinsky et al 1996) (Figure 1). Exosite 1 is located next to the active site and binds fibrin. Exosite 2 acts as the heparin-binding domain.

\section{Pharmacology of bivalirudin}

The DTIs are related in structure to the naturally occurring hirudin molecule. Members of the DTI class of molecules can be classified as univalent or bivalent depending on their interaction with the thrombin molecule. Bivalent DTIs block thrombin at both the active site and exosite-1, whereas the univalent molecules bind only to the active site (Maraganore et al 1990). By reducing the thrombin-mediated activity of platelets, DTIs also exert an anti-platelet effect (Xiao and Theroux 1998; Sarich et al 2003). The DTIs also have the advantage of inhibiting both circulating and clot bound thrombin (Weitz et al 1990, 1998; Bates et al 2000). While circulating thrombin is inactivated by indirect anticoagulants, the clot bound thrombin is not.

Bivalirudin is a synthetic 20 amino acid polypeptide hirudin analog. It displays bivalent and reversible binding to the thrombin molecule (Parry et al 1994). Bivalirudin displays linear pharmacokinetics. Its low oral bioavailability means it is given as an intravenous infusion. There is a small volume of distribution and a short half-life of 25 minutes (White et al 2005). Bivalirudin is predominantly cleared by intracellular proteolysis. The remaining unchanged drug is cleared renally. It has been estimated the renal component of clearance is around 20\% (Reed et al 2002).

The pharmacokinetics and pharmacodynamics of bivalirudin have been evaluated in the setting of renal impairment (Robson et al 2002). In mild renal impairment,

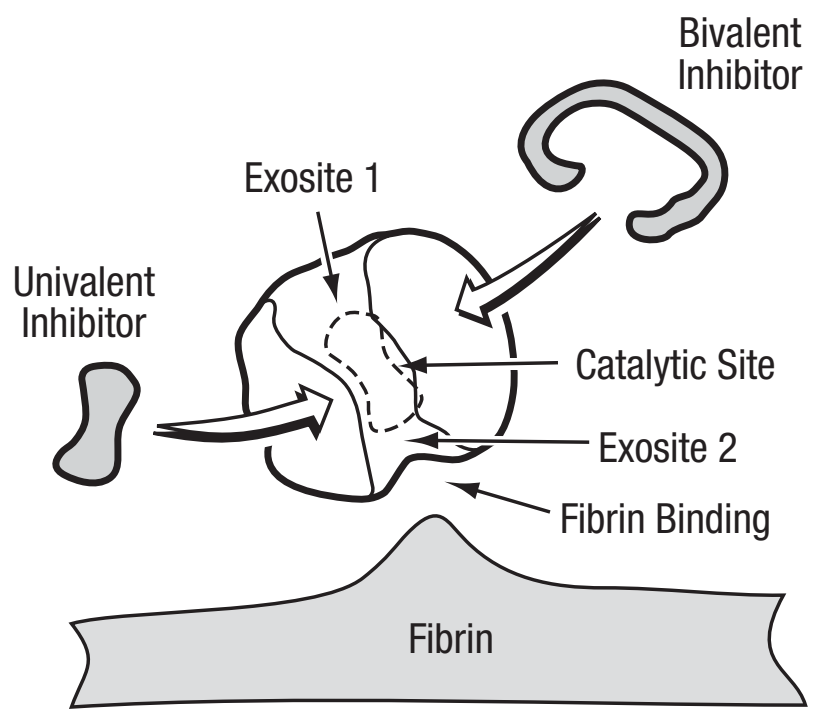

Figure I The activity of DTIs is produced by direct interaction with the thrombin molecule. The bivalent DTIs simultaneously bind the exosite I and the active (catalytic) site. The univalent DTIs interact only with the active site. Abbreviations: DTI, direct thrombin inhibitor.

the clearance of bivalirudin is not reduced enough to be clinically significant. In moderate renal impairment, the clearance of bivalirudin is reduced by $20 \%$. The clinical recommendation is for a $20 \%$ reduction in the infusion dose of bivalirudin in moderate renal impairment.

Activated clotting time (ACT) is used to guide UFH dose in PCI. There is a modest relationship between ACT and bleeding complications with UFH (Brener et al 2004). The relationship between ACT and ischemic complications from PCI with UFH is thought to be reduced by modern antiplatelet and stent technology. The relationship between ACT and bleeding or thrombotic complication does not exist with bivalirudin (Cheneau et al 2004). It appears that monitoring of anticoagulant effect is not required with bivalirudin. Bivalirudin has been shown to reduce the time spent in the recovery area following PCI by 36 minutes compared with heparin ( $\mathrm{p}<0.0001)$ (Schussler et al 2004). In this study, the femoral sheath was removed when the ACT was below 200 seconds in bivalirudin-treated patients, and below 180 seconds in those receiving heparin. In this study, nearly $80 \%$ of patients had an ACT lower than 200 at 2.5 hours. In bivalirudin-treated patients, removal of the femoral sheath at 2 hours appears to be a safe strategy.

UFH and to a much lesser extent LMWHs can be inactivated by platelet factor (PF)-4, a substance released from activated platelets (Eitzman et al 1994). DTIs do not experience platelet factor PF4 inhibition. The UFH/PF4 or $\mathrm{LMWH} / \mathrm{PF} 4$ complex is also the initiator of immunoglobulin 
G mediated heparin induced thrombocytopenia (type II HIT) (Chong 2003). There is no risk of type II heparin induced thrombocytopenia with the DTIs. Bivalirudin has been evaluated as an anticoagulant for PCI in patients with a history of HIT (Mahaffey et al 2003). Among the 52 patient studied, there were no episodes of thrombocytopenia (platelet count $<50 \times 10^{9} / \mathrm{L}$ ), suggesting bivalirudin may be an acceptable alternative to the heparins in this group.

\section{Bivalirudin in ACS and $\mathrm{PCI}$ - the early trials}

Early trials of bivalirudin as an anticoagulant in acute coronary syndromes (ACS) and PCI suggested similar ischemic end points as the heparins, with lower rates of bleeding. The Bivalirudin Angioplasty Trial (BAT) evaluated 4312 patients, randomized to either bivalirudin or heparin, who underwent balloon angioplasty for unstable or postinfarction angina (Bittl et al 1995). In the overall cohort, there was no difference in the primary composite end point of in-hospital death, MI, requirement for intra-aortic balloon pump, or emergency revascularization. In the group undergoing angioplasty following MI, bivalirudin was associated with a lower incidence of the primary end point $(9.1 \%$ vs $14.2 \%, p=0.04)$. There was no difference in the primary end point in patients undergoing angioplasty for unstable angina without MI. Bivalirudin was associated with lower rates of bleeding complications than heparin. These were, retroperitoneal hemorrhage $(0.2 \%$ vs $0.7 \%, \mathrm{p}=0.02)$, need for transfusion $(3.7 \%$ vs $8.6 \%, \mathrm{p}<0.001)$, and major hemorrhage (3.8\% vs $9.8 \%, \mathrm{p}<0.001)$ respectively.

The Comparison of Abciximab with Hirulog for Ischemic Events Trial (CACHET) was the first to examine the safety and efficacy of bivalirudin in the modern PCI environment of stenting and GP IIb/IIIa inhibitors (Lincoff et al 2002). The trial randomized 268 patients to different doses of bivalirudin with planned or provisional abciximab use. The control group was low dose weight-adjusted heparin with abciximab. There was no additional risk of bleeding noted in the bivalirudin groups. When the three bivalirudin groups were pooled, there was a lower incidence of the composite end point of death, MI, revascularization or major bleeding with bivalirudin, $3.4 \%$ vs heparin and abciximab $10.6 \%(\mathrm{p}=0.18)$. While this was a small pilot study, it demonstrated two important points. Firstly that bivalirudin appeared safe to use with GP IIb/IIIa inhibitors. Secondly, bivalirudin was used with only provisional GPIIb/ IIIa inhibitor (24\% in this trial), without a loss of efficacy.
The Randomized Evaluation in PCI Linking Angiomax to Reduced Clinical Events (REPLACE)-1 trial was a pilot study of 1056 patients undergoing elective or urgent PCI (Lincoff et al 2002). Patients were randomized to heparin or bivalirudin. All patients received aspirin and pretreatment with clopidogrel was encouraged. The use of glycoprotein IIb/IIIa inhibitors was at the physician's discretion. The combined end point of death, MI, or repeat revascularization was reduced by $19 \%$ in the bivalirudin-treated patients at 48 hours ( $\mathrm{p}=\mathrm{NS}$ ). The larger REPLACE-2 trial involved 6010 patients (Lincoff et al 2003). This trial was designed to test the non-inferiority of bivalirudin with provisional GP IIb/IIIa inhibitor compared with heparin and GP IIb/ IIIa inhibitor. The cohort studied was undergoing elective PCI or PCI for non-ST elevation ACS. Patients undergoing PCI for ST segment elevation myocardial infarction were not included. Approximately $50 \%$ of patients underwent PCI for an acute coronary syndrome. Multi-vessel intervention was undertaken in around $15 \%$ of patients, and saphenous vein graft intervention was undertaken in $6 \%$ of cases. Patients randomized to the heparin arm were planned to receive a GP IIb/IIIa antagonist (either abciximab or eptifibatide). In those randomized to bivalirudin, GP IIb/ IIIa antagonists were permitted for procedural complications. These included coronary dissection, thrombus formation, unplanned stenting, slow flow, distal embolization and ongoing instability. Provisional GP IIb/ IIIa inhibitor was used in $7.2 \%$ of the bivalirudin group. The primary end point was a composite of death, MI, urgent repeat revascularization, or major in-hospital bleeding by 30 days. There was no significant difference in the primary end point between heparin plus GP IIb/IIIa inhibitor and the bivalirudin group $(10.0 \%$ vs $9.2 \%$; OR $0.92 ; 95 \% \mathrm{CI}$, $0.77-1.09, \mathrm{p}=0.32$ ). A small excess of peri-procedural nonQ wave myocardial infarctions was noted in the bivalirudin group $(6.6 \%$ bivalirudin vs $5.8 \%$ heparin, $\mathrm{p}=0.43)$. This difference was due to a small excess in CKMB elevation 510 times the upper limit of normal. This did not reach statistical significance and the clinical relevance is unclear. There were no identified differences in efficacy noted in the major subgroups of the trial. While there were no significant differences in the ischemic end points between the two groups, there was a significant difference in bleeding complications. There was a $41 \%$ relative reduction in major bleeding among patients treated with bivalirudin $(2.4 \%$ vs $4.1 \%, \mathrm{p}<0.001)$.

The REPLACE- 2 trial has reported end-point data at 6 months and 1 year (Lincoff et al 2004b). At 6 months, there 
was no significant difference in the two groups in the rates of death, myocardial infarction or need for revascularization. At 1 year, there was a non-significant trend towards improved survival in the bivalirudin group. This has alleviated some of the concerns regarding the non-significant trend of increased peri-procedural non-Q wave myocardial infarction with bivalirudin.

A pooled analysis has been performed of the clinical trials evaluating bivalirudin in PCI (Ebrahimi et al 2005). This included 11638 treated patients, 5,861 with bivalirudin and 5,777 with heparin. Bivalirudin was associated with a reduction in the incidence of death, $\mathrm{MI}$, revascularization, and major bleeding (7.8\% vs $10.8 \%, \mathrm{p}<0.001)$ at 48 hours. A benefit in mortality was observed $(0.01 \%$ vs $0.02 \%$, $\mathrm{p}=0.049)$, with a more substantial reduction in major bleeding $(2.7 \%$ vs $5.8 \%, \mathrm{p}<0.001)$.

Bivalirudin appears safe to use with the usual antiplatelet agents aspirin, clopidogrel, and GP IIb/IIIa inhibitors. There were lower clinical events in the bivalirudin group of REPLACE-2 who were pre-treated with clopidogrel (Saw et al 2004). This did not achieve statistical significance in the heparin/GP IIb/IIIa group.

The cohort of patients with renal impairment presenting with acute coronary syndromes are at higher risk for complications. Pooled analyses from BAT, CACHET and REPLACE-1 and an analysis from REPLACE-2 have demonstrated increased risk of bleeding and ischemic events in patient with renal impairment treated with heparin and with combination of a heparin with a GP IIb/IIIa inhibitor (Chew et al 2003, 2005). The relative benefit of bivalirudin with respect to ischemic and bleeding events appears to be maintained at each stratum of renal function. The absolute benefit in terms of ischemic and bleeding complications increased with decreasing creatinine clearance, normal (>90 mL/min) 2.2\%, mild (90-60 mL/min) 5.8\%, moderate (59-30 mL/min) $7.7 \%$, and severe $(<30 \mathrm{~mL} / \mathrm{min}) 14.4 \%$, p trend $<0.001$, interaction $\mathrm{p}=0.044$.

Small studies have been conducted with bivalirudin in the setting of drug eluting stents, brachytherapy and peripheral intervention (Allie et al 2005; Dangas et al 2005; Kuchulakanti et al 2005). Evidence from these studies appears to indicate the safety and efficacy of bivalirudin in these settings.

An economic analysis has been performed on the basis of data from the REPLACE 2 trial (Cohen et al 2004). Costs were analyzed on the basis of market cost of pharmaceuticals and calculated costs of care at the Beth Israel Deaconess Medical Centre. The economic analysis favored bivalirudin.
The absolute cost saving per patients for the period of hospitalization was US\$405. In this analysis, $80 \%$ of the cost saving was due to a reduction in the cost of pharmaceuticals (GP IIb/IIIa inhibitor). This is despite the provisional use of GP IIb/IIIa inhibitor in around 7\% of patients in the REPLACE-2 trial.

Results of the Randomized Trial to Evaluate the Relative Protection against Post-PCI Microvascular Dysfunction and Post-PCI Ischaemia among Anti-Platelet and AntiThrombotic Agents - Thrombolysis in Myocardial Infarction 30 (PROTECT-TIMI 30) trial have recently been published (Gibson et al 2006). This study examined the coronary flow reserve after PCI in the setting of non-ST segment elevation ACS with eptifibatide and either UFH or enoxaparin or bivalirudin monotherapy. The primary end point of coronary flow reserve is a marker of coronary microvascular function. Bivalirudin monotherapy was associated with higher coronary flow reserves than an eptifibatide and heparin strategy ( 1.43 vs $1.33, \mathrm{p}=0.036)$. TIMI perfusion grade was more often normal with eptifibatide treatment compared with bivalirudin $(57.9 \%$ vs $50.9 \%, \mathrm{p}=0.048)$. The duration of ischemia as measured by Holter monitoring was significantly longer in the bivalirudin treated patients (169 vs $36 \mathrm{~min}$, $\mathrm{p}=0.013)$. Bivalirudin was associated with lower rates of TIMI minor bleeding $(0.4 \%$ vs $2.5 \%, \mathrm{p}=0.027)$ and transfusion $(0.4 \%$ vs $4.4 \%, \mathrm{p}<0.001)$ compared with eptifibatide combined with a heparin.

\section{The acuity trial}

The Acute Catheterization and Urgent Intervention Triage Strategy (ACUITY) trial enrolled 13819 patients with moderate to high risk ACS undergoing an invasive strategy (Stone et al 2004; Stone 2006a, b). All patients were treated with aspirin and clopidogrel was encouraged. The timing and dose of clopidogrel was left to the treating physician. Patients were first randomized to one of three groups (Figure 2 ). These were a group of heparins (either enoxaparin or UFH) and GP IIb/IIIa inhibitor, bivalirudin and GP IIb/IIIa inhibitor or bivalirudin alone. The bivalirudin only group had the option of bail out GP IIb/IIIa for thrombotic complications during PCI. The two groups using planned GP IIb/IIIa inhibitors underwent a second randomization to either initial (upstream) GP IIb/IIIa inhibitor therapy or therapy during PCI. The GP IIb/IIIa used upstream were predominantly eptifibatide and tirofiban. The GP IIb/IIIa inhibitors used in the catheterization laboratory were predominantly abciximab and eptifibatide. The dose of 


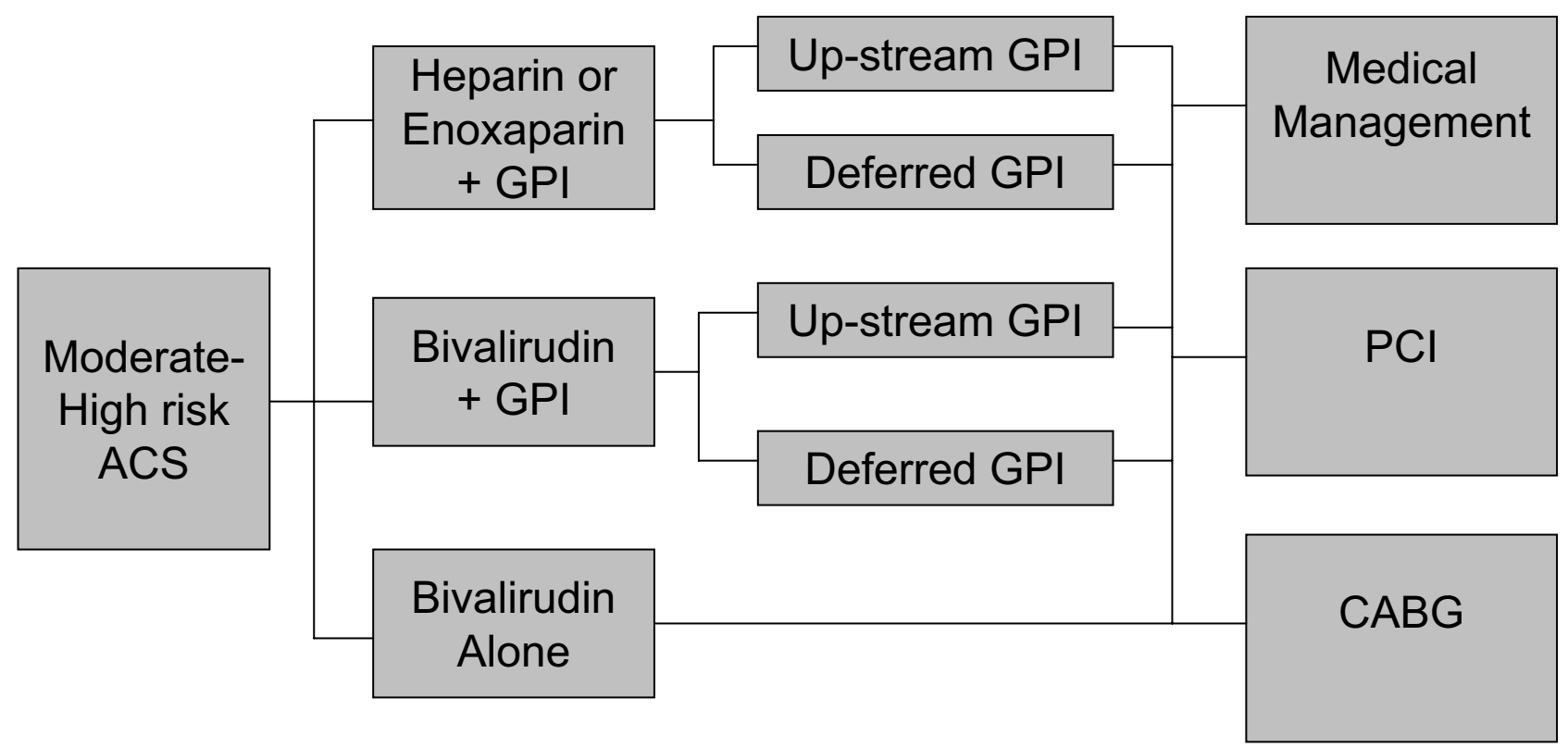

Figure 2 Design of the ACUITY trial. Patients with moderate to high risk ACS were first randomized to one of three groups. For the groups including a GPI, a second randomization occurred to either up-stream or deferred GPI. Angiography was undertaken within 72 hours, and patients were then treated medically, surgically or with $(\mathrm{PCl})$ on clinical grounds.

Abbreviations: ACS, acute coronary syndrome; CABG, coronary artery bypass graft; GPI, glycoprotein Ilb/llla inhibitor; PCl, percutaneous coronary intervention.

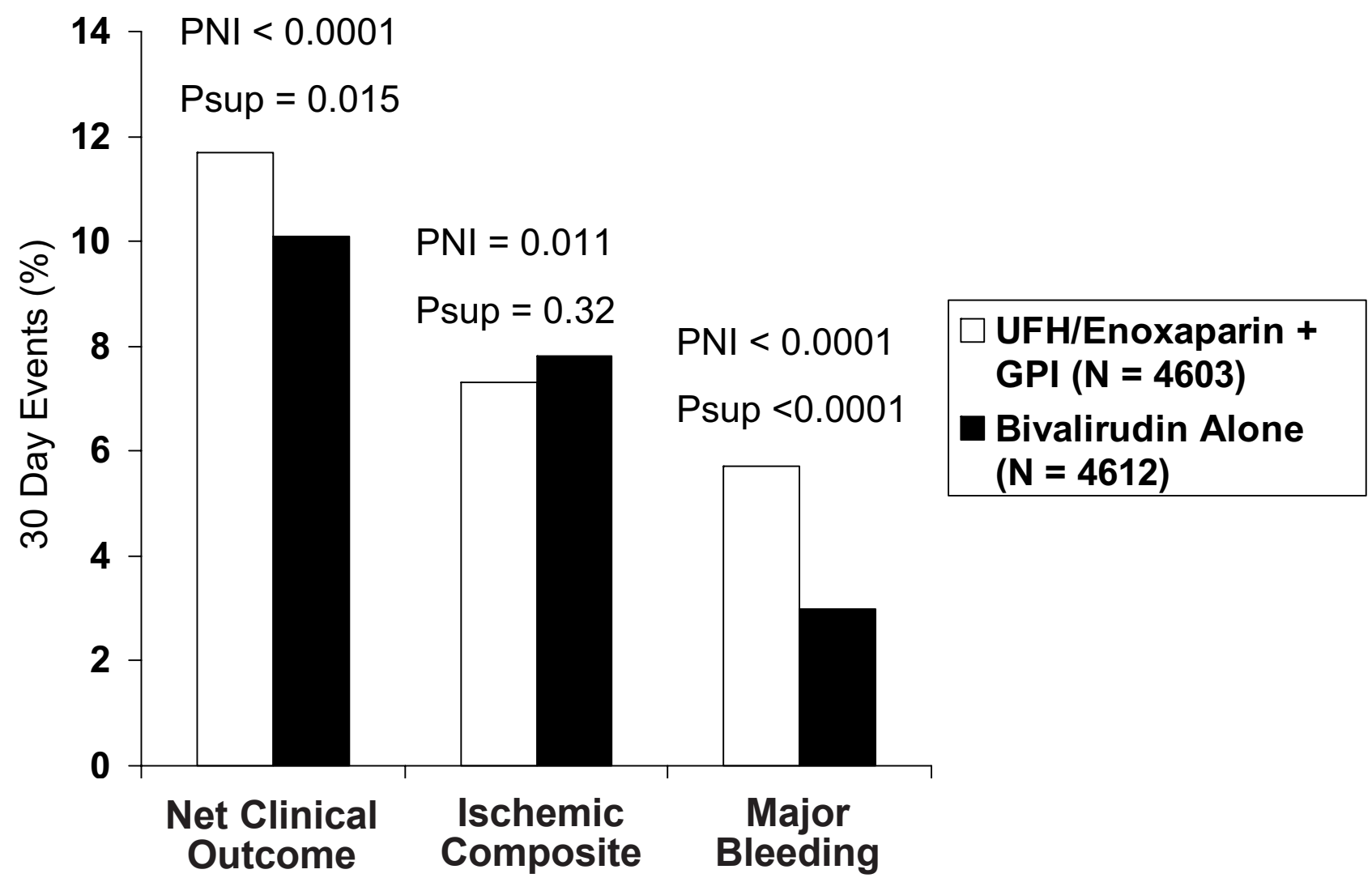

Figure 3 Thirty-day events for UFH/enoxaparin plus GP IIb/Illa inhibitor versus bivalirudin monotherapy in the ACUITY trial. PNI is the non-inferiority P value. Psup is the superiority $P$ value.

Abbreviations: GPI, glycoprotein Ilb/Illa inhibitor; UFH, unfractionated heparin.

bivalirudin was $0.1 \mathrm{mg} / \mathrm{kg} \mathrm{I.V.} \mathrm{bolus} \mathrm{and} \mathrm{then} 0.25 \mathrm{mg} / \mathrm{kg} /$ hour pre-angiography. In the catheterization laboratory, a bolus of $0.5 \mathrm{mg} / \mathrm{kg}$ was given, then infusion at a rate of
$1.75 \mathrm{mg} / \mathrm{kg} / \mathrm{hour}$. Bivalirudin was discontinued at the end of the procedure. There was an option for continued therapy for 4-12 hours if a GP IIb/IIIa inhibitor was not used. 
There were three pre-specified primary end points. The ischemic composite consisted of death, myocardial infarction, and unplanned revascularization. There was a major bleeding end point that included predominantly non coronary bypass related bleeding events. The third was a net clinical benefit, taking into account both the ischemic and bleeding end points. When the heparins with GP IIb/ IIIa inhibitor group was compared with bivalirudin plus GP IIb/IIIa inhibitor, the bivalirudin group was non-inferior with regard to the composite ischemic, major bleeding, and net clinical outcome end points. Preliminary data have been reported in abstract form at the time of publication. The 30day events rates (heparins/GP IIb/IIIa inhibitor vs bivalirudin/GP IIb/IIIa inhibitor) for net clinical outcome were $11.7 \%$ vs $11.8 \%$, ischemic composite $7.3 \%$ vs $7.7 \%$, and major bleeding $5.7 \%$ vs $5.3 \%$ respectively. When the heparins and GP IIb/IIIa inhibitor group was compared with bivalirudin-only therapy, bivalirudin was non-inferior in the triple ischemic endpoint ( $7.3 \%$ vs $7.8 \%, \mathrm{p}=0.32)$. Bivalirudin was superior for major bleeding $(5.7 \%$ vs $3.0 \%$, $\mathrm{p}<0.0001)$. The reduction in bleeding events resulted in bivalirudin being superior in the net clinical end point, RR $0.86(0.77-0.95) p<0.015$. Hence, in this large multicenter trial using modern management for ACS, bivalirudin monotherapy markedly reduced rates of bleeding without loss of efficacy in the ischemic end points (Figure 3).

The ACUITY trial also examined the timing of GP IIb/ IIIa inhibitor use in a second randomization in patients assigned to the GP IIb/IIIa inhibitor groups (Stone 2006a, b). Patients in these two groups were assigned to either receive up-stream GP IIb/IIIa inhibitor or deferred for administration in the catheterization laboratory for the patients undergoing PCI. Previous trials have demonstrated benefits of early (up-stream) GP IIb/IIIa inhibitor in this setting. Early data in abstract form from the ACUITY trial suggested no difference in the 30-day net clinical outcome between upstream and deferred GP IIb/IIIa inhibitor (11.7\% vs $11.7 \%, \mathrm{p}=0.93)$. The deferred GP IIb/IIIa strategy failed to meet non-inferiority for the ischemic composite (7.1 vs $7.9 \%, \mathrm{p}=0.06$ ). There was a significantly higher rate of unplanned revascularization for ischemia $(2.1 \%$ vs $2.8 \%$, $\mathrm{p}=0.03$ ). There was a significant reduction in 30-day major bleeding events in patients randomized to the deferred GP IIb/IIIa strategy ( $6.1 \%$ vs $4.9 \%$, $\mathrm{p}=0.009)$.

\section{Summary}

Multiple clinical trials now demonstrate that bivalirudin is a safe and effective anticoagulant for use in ACS and PCI.
The reduction in bleeding complications compared with heparin-based strategies has been a consistent finding across these studies. This has been demonstrated without loss of efficacy in the prevention of thrombotic complications. Depending on the cost of bivalirudin, there may be economic benefit created through a reduction in the need for GP IIb/ IIIa inhibitors and reduced rates of bleeding in both ACS and PCI.

\section{Disclosures}

The authors have no conflicts of interest.

\section{References}

Allie DE, Hebert CJ, Lirtzman MD, et al. 2005. A safety and feasibility report of combined direct thrombin and GP IIb/IIIa inhibition with bivalirudin and tirofiban in peripheral vascular disease intervention: treating critical limb ischemia like acute coronary syndrome. J Invasive Cardiol, 17:427-432.

Andersen DL, Greenberg, Fujikawa K, et al. 1999. Protease-activated receptor 1 is the primary mediator of thrombin-stimulated platelet procoagulant activity. Proc Nat. Acad Sci U S A, 96:11189-93.

Antman EM, McCabe CH, Braunwald E. 2002. Bivalirudin as a replacement for unfractionated heparin in unstable angina/non-STelevation myocardial infarction: observations from the TIMI 8 trial. The Thrombolysis in Myocardial Infarction. Am Heart J, 143:22934.

Bates SM, Weitz JI. 2000. The mechanism of action of thrombin inhibitors. J Invasive Cardiol, 12(Suppl F): F27-32.

Becker RC. 2005. Understanding the dynamics of thrombin in cardiovascular disease: pathobiology and biochemistry for the clinician. Am Heart J, 149(Supp11):S2-8.

Bittl JA, Chaitmen BR, Feit F, et al. 2001. Bivalirudin versus heparin during coronary angioplasty for unstable or postinfarction angina: Final report reanalysis of the Bivalirudin Angioplasty Study. Am Heart $J, 142: 952-59$.

Bittl JA, Strony J, Brinker JA, et al. 1995. Treatment with bivalirudin (Hirulog) as compared with heparin during coronary angioplasty for unstable or postinfarction angina. Hirulog Angioplasty Study Investigators. $N$ Engl J Med, 333:764-769.

Brener SJ, Moliterno DJ, Lincoff AM, et al. 2004. Relationship between activated clotting time and ischemic or hemorrhagic complications: analysis of 4 recent randomized clinical trials of percutaneous coronary intervention. Circulation, 110:994-8.

Cheneau E, Canos D, Kuchulakanti PK, et al. 2004. Value of monitoring activated clotting time when bivalirudin is used as the sole anticoagulation agent for percutaneous coronary intervention. Am J Cardiol, 94:789-92.

Chew DP, Bhatt DL, Kimball W, et al. 2003. Bivalirudin provides increasing benefit with decreasing renal function: a meta-analysis of randomized trials. Am J Cardiol, 92:919-23.

Chew DP, Lincoff AM, Gurm H, et al. 2005. Bivalirudin versus heparin and glycoprotein IIb/IIIa inhibition among patients with renal impairment undergoing percutaneous coronary intervention (a subanalysis of the REPLACE-2 trial). Am J Cardiol, 95:581-5.

Chong BH. 2003. Heparin-induced thrombocytopenia. J Thromb Haemost, $1: 1471-8$

Cohen DJ, Lincoff AM, Lavelle TA, et al. 2004. Economic evaluation of bivalirudin with provisional glycoprotein IIB/IIIA inhibition versus heparin with routine glycoprotein IIB/IIIA inhibition for percutaneous coronary intervention: results from the REPLACE-2 trial. $J$ Am Coll Cardiol, 44:1792-800. 
Dangas G, Lasic Z, Mehran R, et al. 2005. Effectiveness of the concomitant use of bivalirudin and drug-eluting stents (from the prospective, multicenter BivAlirudin and Drug-Eluting STents [ADEST] study). Am J Cardiol, 96:659-63.

De Candia E, Hall SW, Rutella S, et al. 2001. Binding of thrombin to glycoprotein Ib accelerates the hydrolysis of Par-1 on intact platelets. J Biol Chem, 276:4692-98.

Direct Thrombin Inhibitor Trialists' Collaborative Group. 2002. Direct thrombin inhibitors in acute coronary syndromes: principal results of a meta-analysis based on individual patients' data. Lancet, 359:294302.

Ebrahimi R, Lincoff AM, Bittl JA, et al. 2005. Bivalirudin vs Heparin in Percutaneous Coronary Intervention: A Pooled Analysis. J Cardiovasc Pharmacol Ther, 10:209-16.

Eitzman DT, Chi L, Saggin L, et al. 1994. Heparin neutralization by platelet-rich thrombi. Role of platelet factor 4. Circulation, 89:15239.

Gibson CM, Morrow DA, Murphy SA, et al. 2006. A randomized trial to evaluate the relative protection against post-PCI microvascular dysfunction, ischaemia and inflammation among anti-platelet and antithrombotic agents: the PROTECT-TIMI 30 Trial. $J$ Am Coll Cardiol, 47:2364-73.

Kuchulakanti P, Wolfram R, Torguson R, et al. 2005. Bivalirudin compared with IIb/IIIa inhibitors in patients with in-stent restenosis undergoing intracoronary brachytherapy. Cardiovasc Revasc Med, 6:154-9.

Lincoff AM, Bittl JA, Harrington RA. 2003. Bivalirudin and provisional glycoprotein IIb/IIIa blockade compared with heparin and planned glycoprotein IIb/IIIa blockade during percutaneous coronary intervention: REPLACE-2 randomized trial. JAMA, 289:853-63.

Lincoff AM, Bittl JA, Kleiman NS, et al. 2004b. Comparison of Bivalirudin Versus Heparin During Percutaneous Coronary Intervention (the Randomized Evaluation of PCI Linking Angiomax to Reduced Clinical Events [REPLACE]-1 Trial. Am J Cardiol, 93:1092-6.

Lincoff AM, Kleiman NS, Kereiakes DJ, et al. 2004a. Long-term efficacy of bivalirudin and provisional glycoprotein IIb/IIIa blockade vs heparin and planned glycoprotein IIb/IIIa blockade during percutaneous coronary revascularization: REPLACE-2 randomized trial. JAMA, 292:696-703.

Lincoff AM, Kleiman NS, Kottke-Marchant K, et al. 2002. Bivalirudin with planned or provisional abciximab versus low-dose heparin and abciximab during percutaneous coronary revascularization: results of the Comparison of Abciximab Complications with Hirulog for Ischemic Events Trial (CACHET). Am Heart J, 143:847-53.

MacFarlane RG. 1964. An enzymatic cascade in the blood clotting mechanism, and its function as a biological amplifier. Nature, 202:49899

Mahaffey KW, Lewis BE, Wildermann NM, et al. 2003. The anticoagulant therapy with bivalirudin to assist in the performance of percutaneous coronary intervention in patients with heparin-induced thrombocytopenia (ATBAT) study: main results. J Invasive Cardiol, 15:611-6.

Maraganore JM, Bourdon P, Jablonski J, et al.1990. Design and characterization of hirulogs: a novel class of bivalent peptide inhibitors of thrombin. Biochemistry, 29:7095-101.

Parry MA, Maraganore JM, Stone SR. 1994. Kinetic mechanism for the interaction of Hirulog with thrombin. Biochemistry, 33:14807-14.
Reed MD, Bell D. 2002. Clinical pharmacology of bivalirudin. Pharmacotherapy, 22:S105-11.

Robson R, White H, Aylward P, et al. 2002. Bivalirudin pharmacokinetics and pharmacodynamics: effect of renal function, dose, and gender. Clin Pharmacol Ther, 71:433-9.

Sarich TC, Wolzt M, Eriksson UG, et al. 2003. Effects of ximelagatran, an oral direct thrombin inhibitor, r-hirudin and enoxaparin on thrombin generation and platelet activation in healthy male subjects. $J \mathrm{Am}$ Coll Cardiol, 41:557-64.

Saw J, Lincoff AM, DeSmet W, et al. 2004. Lack of clopidogrel pretreatment effect on the relative efficacy of bivalirudin with provisional glycoprotein IIb/IIIa blockade compared to heparin with routine glycoprotein IIb/IIIa blockade: a REPLACE-2 substudy. $J$ Am Coll Cardiol, 44:1194-9.

Schussler JM, Cameron CS, Azam A, et al. 2004. Effect of bivalirudin on length of stay in the recovery area after percutaneous coronary intervention compared with heparin alone, heparin + abciximab, or heparin + eptifibatide. Am J Cardiol, 94:1417-19.

Smith SC, Feldman TE, Hirshfeld JW et al. 2005. ACC/AHA/SCAI 2005 guideline update for percutaneous coronary intervention [online]. Accessed 25 Sept 2006. URL: http://www.acc.org.

Soslau G, Class R, Morgan DA, et al. 2001. Unique pathway of thrombininduced platelet aggregation mediated by glycoprotein Ib. J Biol Chem, 276:21173-83.

Stone GW, Bertrand M, Colombo A, et al. 2004. Acute catheterization and urgent Intervention triage strategy (ACUITY) trial: study design and rationale. Am Heart $J$, 148:764-75.

Stone GW. 2006a. Prospective, Randomized Comparison of Heparin Plus IIb/IIIa Inhibition and Bivalirudin With or Without IIb/IIIa Inhibition in Patients With Acute Coronary Syndromes: The ACUITY Trial. American College of Cardiology Scientific Sessions 2006. Late Breaking Clinical Trials Session I.

Stone GW. 2006b. Prospective, Randomized Comparison of Routine Upfront Initiation Versus Selective Use of Glycoprotein IIb/IIIa Inhibitors in Patients With Acute Coronary Syndromes: The ACUITY Timing Trial. i2 Summit 2006 Late-Breaking Clinical Trials II.

Tulinsky A.1996. Molecular interactions of thrombin. Semin Thromb Hemost, 22:117-24.

Weitz JI, Hudoba M, Massel D, et al. 1990. Clot-bound thrombin is protected from inhibition by heparin-antithrombin III but is susceptible to inactivation by antithrombin III-independent inhibitors. $J$ Clin Invest, 86:385-91.

Weitz JI, Leslie B, Hudoba M. 1998. Thrombin binds to soluble fibrin degradation products where it is protected from inhibition by heparinantithrombin but susceptible to inactivation by antithrombinindependent inhibitors. Circulation, 97:544-52.

White CM. 2005. Thrombin-directed inhibitors: pharmacology and clinical use. Am Heart J, 149:S54-60.

White H. 2001. Thrombin-specific anticoagulation with bivalirudin versus heparin in patients receiving fibrinolytic therapy for acute myocardial infarction: the HERO-2 randomised trial. Lancet, 358(9296):185563.

Xiao Z, Theroux P. 1998. Platelet activation with unfractionated heparin at therapeutic concentrations and comparisons with a low-molecularweight heparin and with a direct thrombin inhibitor. Circulation, 97:251-6. 
